\title{
Analysis of Influencing Factors for Sliding Wear-Fatigue Damage Interaction
}

\author{
Yu-Tao YAN ${ }^{\mathrm{a}}$, Yuan-Jun XU ${ }^{\mathrm{b}}$, Xiao-Lin QIAN $^{\mathrm{c}}$ \\ School of Mechanical Engineering \& Automation, Northeastern University, 110819, China \\ aytyan@mail.neu.edu.cn, b969605004@qq.com, ${ }^{\text {c} 1099551759 @ q q . c o m ~}$
}

\section{Keywords: Sliding Wear, Fatigue Damage, Interaction, Influencing Factor.}

\begin{abstract}
The variable regular for sliding wear under load, sliding velocity, temperature and surface roughness and fatigue damage under load, sliding velocity and surface roughness by mass experimental datum were established. The analytic model for sliding wear-fatigue damage interaction was established. The results show that the contact stress increases with sliding velocity increasing while the sliding velocity is less than $5 \mathrm{~mm} / \mathrm{s}$, the contact stress is steady while sliding velocity is more than $5 \mathrm{~mm} / \mathrm{s}$, the contact stress increases with friction coefficient increasing under same sliding velocity. The shear stress increases with increasing of sliding velocity while it is less than $5 \mathrm{~mm} / \mathrm{s}$, then the shear stress is steady while sliding velocity is more than $7.5 \mathrm{~mm} / \mathrm{s}$. The logarithmic fatigue life decreases with increasing of load, and expresses liner relation, the process of wear-fatigue interaction damage is similarly to the process of fatigue damage.
\end{abstract}

\section{Introduction}

It is well known that the sliding wear and fatigue is two kinds typical failure mode for mechanical parts under varying stress, they widely consist in multifarious mechanical equipments, and influence the mechanical production reliability, security and operating life, and so on[1-3]. At the present time, the mechanical design criteria is mostly single failure mode. With the development of science and technology and the more high requirements of engineering, the need cannot be satisfied by single design criteria.

The tribo-fatigue was firstly investigated in wheel-railway contact surface for undee wear and contact fatigue in Europe, the tribo-fatigue conception is brought forward by the sosnovsky of scientist of White Russia. The properties of anti-fatigue or anti-wear of materials under wear-fatigue interaction is different than single wear or fatigue. The characteristic is defined tribo-fatigue positive or negative effects, the positive effects shows that the anti-fatigue properties of the system of load-friction pairs and its elements is varied owing to friction and wear, the negative effects shows that the anti-wear properties of the system of load-friction pairs and its elements is varied owing to alternate stress and strain[4]. The dynamics model of tribo-fatigue system has been established based on mass experimental datum, the astable deformation of tribo-fatigue system has been described, a method of preventing damage of wheel-rail wave has been brought forward [5].

\section{Analysis for Sliding Wear}

The influencing factors on tribological properties of the material may be divided into two categories, material attribute and running conditions. The material attribute includes surface hardness, crystal structure and intersolubility, plasticity, toughness, surface texture and material defect. The running conditions include load, sliding velocity, test temperature, surface roughness, lubricant, impact, vibration and so on.

\section{Load}

Fig.1 shows that the friction coefficient increases with load increasing, and the friction coefficient drive to stabilization while load reaching some value. The wear rate gradually increases 
with load increasing. The influence of load to wear to different wear mechanism was analyzed by three aspects. Firstly, the actual contact area and contact microcosmic prominence were increased with load increasing, that lead to the adhesion and Archard adhesion wear mechanism increasing. Secondly, the plastic deformation of wear surface become more serious with load increasing, that lead to plastic deformation work by friction draft and surface damage increasing, the depth of nucleus by hole grown and grinding thickness owing to flake layer wear increasing. Thirdly, with load increasing, the press-in depth of microcosmic prominence, actual contact area and the wear increase according to fatigue wear mechanism and abrasion wear for considering microcosmic prominence.

\section{Sliding Velocity}

The Variation of friction coefficient and wear rate with sliding velocity is shown Fig.2. With sliding velocity increasing, the friction coefficient increase, then decrease, the wear rate continuously increase. Under low sliding velocity, the augmentation gradient is bigger. So, with sliding velocity increasing, the influence of sliding velocity to friction and wear by the different wear mechanism mostly include oxidation wear, adhesion wear and surface deformation. With sliding velocity increasing, the temperature of contact surface increase, the wear rate increase, too.

\section{Test Temperature}

The Variation of friction coefficient and wear rate with test temperature is shown Fig.3. The friction coefficient gradually minish, then gradually increase with test temperature increasing, the friction coefficient is the minimum at $430^{\circ} \mathrm{C}$. With test temperature increasing, the wear rate gradually increases. It was found that the variety of temperature produces metal surface oxidation, adsorption and the variety of mechanism character, influences metal wear. The higher of temperature, the faster of metal oxidation speed. The large test data shows that the protective film was made between friction surface, the friction and wear was diminished while the test temperature exceeds $300^{\circ} \mathrm{C}$. While the influence of test temperature to wear is analyzed, the adhesion of the friction surface, the metal material attribute and interaction between friction surface and environment etc must be synchronously considered.

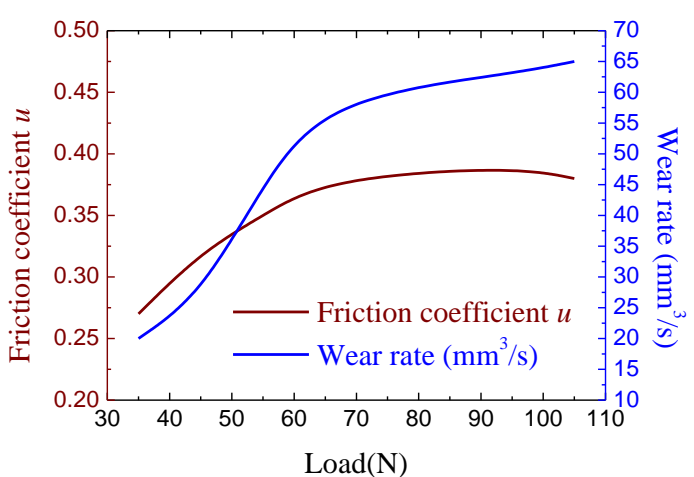

Fig.1 Friction Coefficient and Wear Rate vs. Load

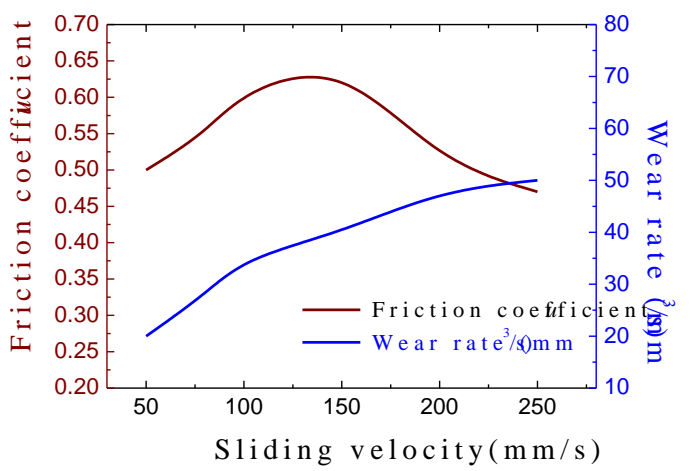

Fig.2 Friction Coefficient and Wear Rate $v s$. Sliding Velocity

\section{Surface Roughness}

The Variation of friction coefficient and wear rate with surface roughness is shown Fig.4. With the increase of surface roughness, the friction coefficient gradually increases then fleetly descend. The wear rate relaxedly increases, then fleetly increases, after the wear rate receives a maximum value, begins to descend. The investigation result shows the bigger the surface roughness, the friction resistance is greater, wear more quickly, the wear resistance is worse. 


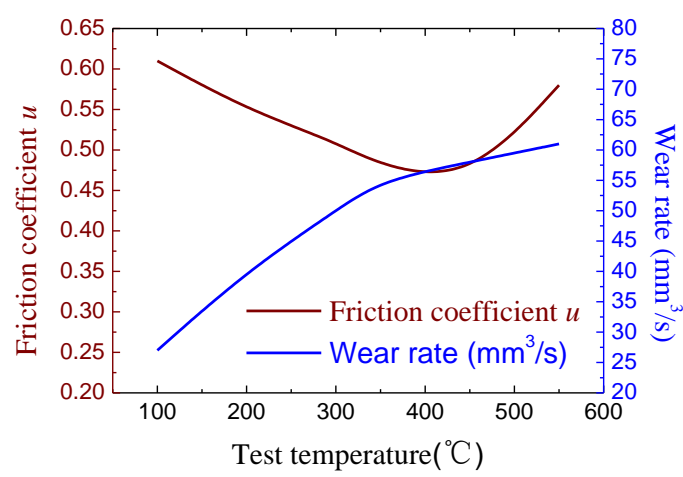

Fig.3 Friction Coefficient and Wear Rate $v s$. Test Temperature

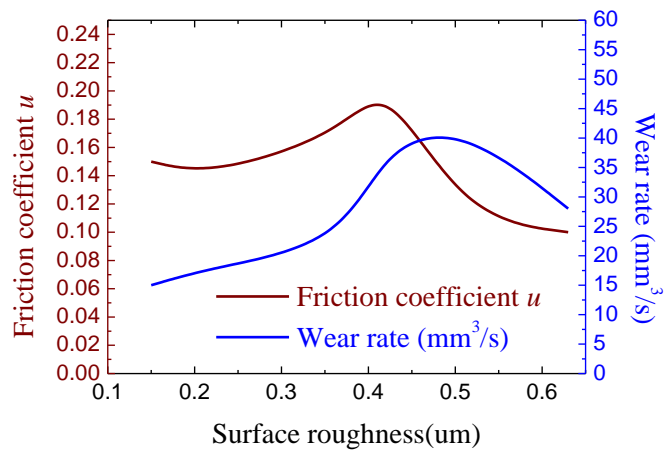

Fig.4 Friction Coefficient and Wear Rate $v s$. Surface Roughness

\section{Analysis for fatigue damage}

\section{Load}

The influence of load to fatigue mostly includes load type, load frequency and the mean stress. To load type, the fatigue limit of tension/compression condition is lower than bend condition, the reason is that the tensile stress and compression stress is the maximal in the total cross-section, but the bending stress varies according to definite gradient. So the quantity of fault in material is different in the maximal stress region, the fatigue limit is lower in multi fault region.

To load frequency, the Variation of fatigue limit with frequency for several metal materials is shown Fig.5. To nonferrous materials, the influence of frequency to fatigue limit is very small. To carbon steel materials, the fatigue limit is steady while the frequency is less than $1000 \mathrm{~Hz}$, the carbon content has obvious impact to fatigue limit. To mean stress, the stress amplitude is a determinant factor to fatigue strength under symmetrical cycle load. The fatigue strength is reduced under tension mean stress. The fatigue strength is increased under compress mean stress.

\section{Test Temperature}

The Fig. 6 shows the variation of fatigue limit of several kinds of steel with the test temperature. The influence for test temperature to fatigue limit is no significant counts at $200{ }^{\circ} \mathrm{C}$. The fatigue limit of materials fleetly descend with test temperature at exceeding $400{ }^{\circ} \mathrm{C}$. The test temperature at maximal value of fatigue limit is different to different carbon content materials.

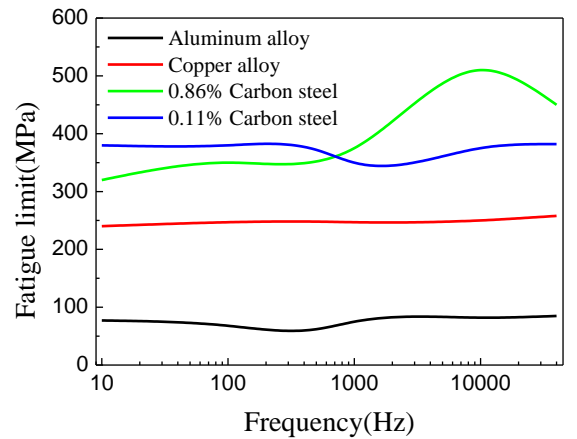

Fig.5 Fatigue Limit $v s$. Frequency

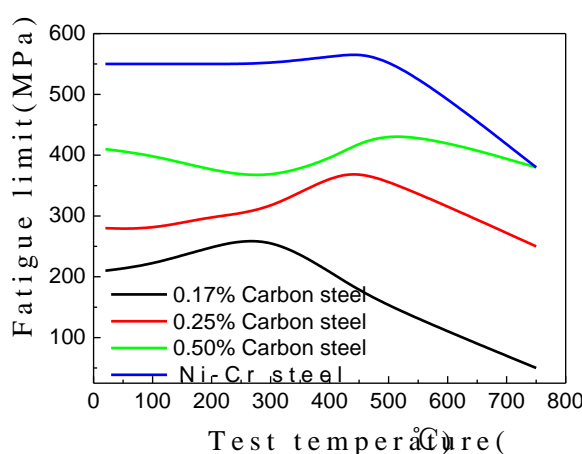

Fig.6 Fatigue Limit vs. Test Temperature

\section{Surface Roughness}

The mass research results show that the larger the surface roughness, the lower the fatigue strength. The surface roughness can generate microcosmic stress concentration, leading to fatigue 
strength decreasing from a macro point of view. The crack formation life can be shortened on account of surface roughness from the micro point of view. The influence of surface roughness to fatigue strength for the high tensile strength materials is very obvious.

\section{Analysis of Sliding Wear-fatigue Damage}

The analysis of the sliding wear-fatigue damage is investigated by ANSYS and FE-SAFE. The molding material is 45 steel, its Young's modulus is $210 \mathrm{GPa}$, its Poisson's ratio is 0.3 , its tensile strength is $600 \mathrm{MPa}$. One aspect of the cylinder is fixed, and one end is applied to load of tensile compression, the normal load is applied the exterior surface of cirque. The sliding velocity is simulated by displacement load and solving time, the range of sliding velocity is $1 \sim 20 \mathrm{~mm} / \mathrm{s}$, the model of finite element analysis is established (Fig.7).

The variation of maximum contact stress with sliding velocity and friction coefficient is shown Fig.8. The contact stress increases with sliding velocity increasing. The variation is approximate 45 degrees liner while the sliding velocity is less than $3 \mathrm{~mm} / \mathrm{s}$, the variation is approximate 75 degrees liner while the sliding velocity is between $3 \sim 5 \mathrm{~mm} / \mathrm{s}$, the contact stress is steady while sliding velocity is more than $5 \mathrm{~mm} / \mathrm{s}$. The contact stress increases with friction coefficient increasing under same sliding velocity.

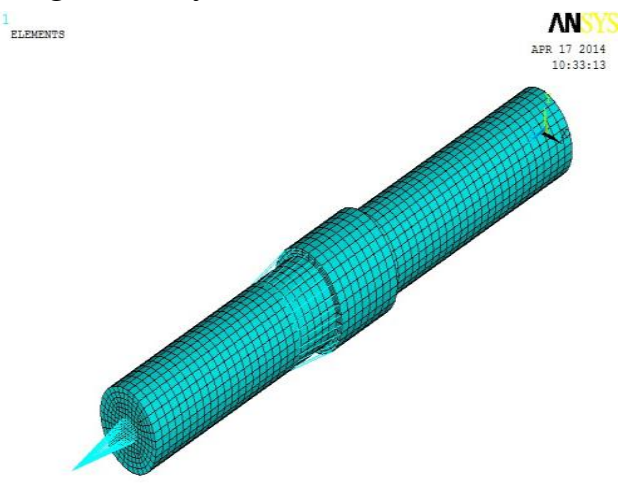

Fig.7 Model of Finite Element Analysis

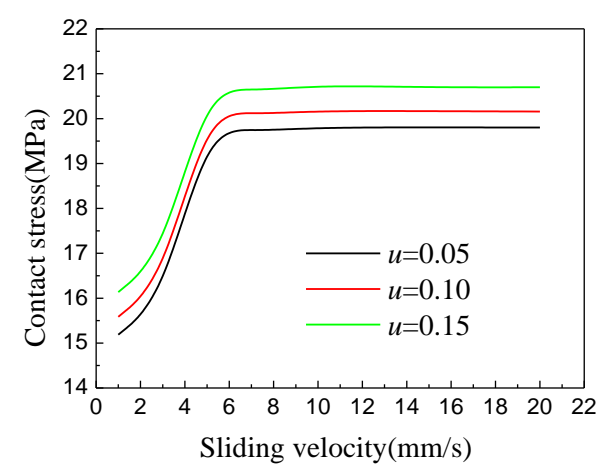

Fig.8 Variation of Maximum Contact Stress with Sliding Velocity and Friction Coefficient

\section{Summary}

The analytic model for sliding wear-fatigue damage interaction was established. The contact stress increases with sliding velocity increasing while the sliding velocity is less than $5 \mathrm{~mm} / \mathrm{s}$, the contact stress is steady while sliding velocity is more than $5 \mathrm{~mm} / \mathrm{s}$. The contact stress increases with friction coefficient increasing under same sliding velocity. The shear stress increases with increasing of sliding velocity while it is less than $5 \mathrm{~mm} / \mathrm{s}$, then the shear stress is steady while sliding velocity is more than $7.5 \mathrm{~mm} / \mathrm{s}$. The logarithmic fatigue life decreases with increasing of load, and expresses liner relation, the process of wear-fatigue interaction damage is similarly to the process of fatigue damage. To interaction for sliding wear-fatigue damage, the master influencing factors is load and surface roughness.

\section{Acknowledgements}

This work was financially supported by the Liaoning Natural Science Foundation of China under Grant No.2013020034.

\section{References}

[1]Y. J. Xu: The life predication model of sliding wear-fatigue combined effects. (in Chinese). 
[2]A. V. Bahdanovich, S. A. Tyurin, V. A. Andriyashin, and A. M. Elavyi: Wear-fatigue test methods and their significance, Strength of Materials, Vol. 41, No 1(2009), p. 95-101.

[3]K. V. Frolov, N. A. Makhutov: Wear-fatigue damage and its prediction, Springer, 2005.

[4]L. A. Sosnovskiy, Wan Zhen Gao: Wear-fatigue, Proceedings of III International Symposium on Tribo-Fatigue, Beijing, China, October 22-26, Hunan University Press, 2000, 1-16.

[5]S. S. Sherbakov: Dynamics of tribo-fatigue system. National Academy of Sciences of Belarus, Vol. 2, No 1, (2009), p. 76-80. 